\title{
Pendidikan Kesehatan tentang Terapi Komplementer dalam Kehamilan
}

\author{
Fatihatul Hayati \\ Program Studi DIII Kebidanan, STIKes Baiturrahim Jambi \\ email: fatihatulhayatianam@gmail.com
}

Submitted : 11/12/2020

Accepted: 21/06/2021

Published: 28/06/2021

\begin{abstract}
Complementary therapy in health care is a non-conventional treatment aimed at increasing the degree of public health. The terpi includes promotional, preventive, curative, and rehabilitative efforts that have proven their quality of safety, and effectiveness based on research and science (Evidence Based Medicine). In complementary therapy, the therapist treats various diseases or complaints using traditional techniques and is not done by surgery and drugs or pharmaceutical products, but by utilizing various types of therapy and herbs. The use of complementary therapies in the field of midwifery must be proven safe by research. Pregnant women are a group that is recommended to take advantage of complementary therapy or medicine in dealing with perceived complaints, because complementary therapy can avoid the side effects of conventional medicine and have great control over their own health. Although traditional / complementary medicine is relatively safer, it does not mean that it does not pose a risk, therefore pregnant women must have adequate knowledge about the use of safe complementary therapies during pregnancy. Health education on complementary therapies in pregnancy is provided by extension methods when pregnant women carry out motherhood classes in the working area of Puskesmas Putri Ayu, Jambi City. This activity was carried out in conjunction with the clinical practice of students of D III Midwifery Stikes Baiturrahim Jambi.
\end{abstract}

Keywords: complementary therapies, knowledge, pregnant mother

\begin{abstract}
Abstrak
Terapi komplementer dalam pelayanan kesehatan merupakan pengobatan non konvensional yang ditujukan untuk meningkatkan derajat kesehatan masyarakat. Terpi tersebut meliputi upaya promotif, preventif, kuratif, dan rehabilitatif yang telah teruji kualitas kemanan, dan efektifitasnya berdasarkan penelitian dan keilmuan (Evidence Based Medicine). Dalam terapi komplementer terapis mengatasi berbagai penyakit atau keluhan dengan teknik tradisional dan tidak dilakukan dengan tindakan bedah dan obat atau produk farmasi, namun dengan memanfaatkan berbagai jenis terapi dan herbal. Pemanfaatan terapi komplementer dalam bidang kebidanan harus dibuktikan keamanannya dengan penelitian. Ibu hamil merupakan kelompok yang dianjurkan memanfaatkan terapi atau pengobatan komplementer dalam mengatasi keluhan yang dirasakan, karena dengan terapi komplementer dapat menghindari efek samping pengobatan konvesional dan memiliki kontrol yang besar terhadap kesehatan sendiri. Meskipun pengobatan tradisional/ komplementer relatif lebih aman namun bukan berarti tidak menimbulkan risiko, untuk itu ibu hamil harus memiliki pengetahuan yang mumpuni tentang pemanfaatan terapi komplementer yang aman selama kehamilan. Pendidikan kesehatan tentang terapi komplementer dalam kehamilan diberikan dengan metode penyuluhan saat ibu hamil melaksanakan kelas ibu di wilayah kerja Puskesmas Putri Ayu Kota Jambi. Kegiatan ini dilaksanakan bersamaan dengan praktik klinik mahasiswa D III Kebidanan Stikes Baiturrahim Jambi.
\end{abstract}

Kata Kunci: ibu hamil, pengetahuan, terapi komplementer

\section{PENDAHULUAN}

Terapi komplementer dalam pelayanan kesehatan merupakan pengobatan non konvensional yang ditujukan untuk meningkatkan derajat kesehatan masyarakat. Terpi tersebut meliputi upaya promotif, preventif, kuratif, dan rehabilitatif yang telah teruji kualitas kemanan, dan 
efektifitasnya berdasarkan penelitian dan keilmuan (Evidence Based Medicine). Dalam terapi komplementer terapis mengatasi berbagai penyakit atau keluhan dengan teknik tradisional dan tidak dilakukan dengan tindakan bedah dan obat atau produk farmasi, namun dengan memanfaatkan berbagai jenis terapi dan herbal.

Terapi komplementer adalah pengobatan tradisional yang sudah diakui dan dapat dipakai sebagai pendamping terapi konvensional medis. Dalam pelaksanaannya terapi komplementer dapat dilakukan bersamaan dengan terapi medis.( Moyad, 2009)

Penelitian membuktikan bahwa terapi komplementer dapat menjadi solusi untuk mengurangi rasa ketidaknyamanan bahkan dapat menyembuhkan beberapa penyakit. Terapi ini lebih aman dan memiliki risiko yang lebih rendah dibandingkan dengan obat modern dengan bahan kimia. namun terkadang terdapat juga pasien yang menggunakan pengobatan tradisional atau komplementer tetapi tidak mendapatkan kesembuhan sesuai harapan bahkan menjadikan penyakitnya lebih parah. Untuk itu perlu dipahami tentang pemanfaatan terapi komplementer karena meskipun pengobatan komplementer relatif lebih aman namun bukan berarti tidak menimbulkan risiko .(Onyapat, 2011).

Ibu hamil pada umumnya mengalami beberapa keluhan dan ketidaknyamanan selama kehamilan, yang dapat diatasi dengan terapi komplementer. Diantara ketidaknyamanan tersebut antara lain :

a. Trimester pertama

Pada kehamilan trimester pertama merupakan proses awal dari kehamilan. Pada minggu inilah proses terjadinya kehamilan ditentukan. Setelah terjadi konsepsi, tubuh ibu akan banyak berubah dalam 3 bulan pertama kehamilan. Janin berkembang didalam rahim ibu akan timbul keluhan-keluhan dan tidak harus dialami oleh ibu, seperti perasaan mual, nyeri punggung, lelah, perubahan mood, keram kaki, sering berkemih dan konstipasi.

b. Trimester kedua

Saat kehamilan menginjak trimester kedua, maka tubuh mulai beradaptasi dengan perubahan yang terjadi. Saat-saat ini merupakan saat yang menyenangkan karena keluhan sudah mulai berkurang. Perubahan yang terjadi seperti perut mulai kelihatan membesar, pergelangan kaki mulai terlihat oedema, mulai terjadi pigmentasi kulit, mulai terasa nyeri di pinggang, mulai merasa gerakan kecil.

c. Trimester ketiga

Pada trimester ini biasanya ibu mulai merasakan berbagai keluhan yang berkaitan dengan perubahan tubuhnya dan berkaitan dengan proses persalinan. Perubahan yang terjadi seperti peningkatan frekuensi berkemih, sesak nafas, merasakan kontraksi, payudara semakin membesar, otot da ligamentum semakin stretch sehingga sering terasa pegal merasakan tekanan pada bagian bawah dan terjadi oedema

Di Indonesia saat ini menggunakan istilah pelayanan kesehatan tradisional, alternatif dan komplementer, dimana pelayanan kesehatan tradisional merupakan seluruh pelayanan yang ada di masyarakat, terbagi dalam 2 kelompok besar yaitu pelayanan kesehatan tradisional ramuan dan pelayanan kesehatan tradisional keterampilan. Hal yang berkembang saat ini adalah pelayanan kesehatan alternatif dan komplementer dimaksudkan sebagai pelayanan yang sudah dinyatakan aman dan bermanfaat serta dapat diintegrasikan dalam fasilitas pelayanan kesehatan. .(Onyapat, 2011).

Ibu hamil merupakan kelompok yang dianjurkan memanfaatkan terapi atau pengobatan komplementer dalam mengatasi keluhan yang dirasakan, karena dengan terapi komplementer dapat menghindari efek samping pengobatan konvesional dan memiliki kontrol yang besar terhadap 
kesehatan sendiri. ${ }^{3}$ Adapun pelayanan terapi komplementer dalam kehamilan diantara :

a. Herbal (jahe) dalam mengatasi mual

b. Aromaterapi

c. Hipnoterapi antenatal

d. Yoga kehamilan

e. Terapi musik

Pemanfaatan terapi komplementer oleh ibu hamil dipengaruhi oleh media massa, informasi dari sebuah produk, rekomendasi keluarga dan teman, sifat alami manusia yang ingin selalu mencoba hal-hal baru serta kemudahan akses pada pengobatan ini dapat mempengaruhi persepsi seseorang untuk menggunakan CAM karena dinilai alami dan aman digunakan.(Onyapat, 2011).

Tugas bidan dalam pelayanan kehamilan meliputi promotif, preventif, deteksi dini komplikasi dan penanganan kegawatdaruratan. Terapi komplementer dapat dilakukan pada tahap promotif dan preventif, misalnya saja pada ibu hamil dilakukan prenatal yoga dengan harapan ibu yang mengikuti prenatal yoga selama kehamilan akan membuat ibu menjadi lebih bugar, lebih sehat sehingga dapat mengurangi ketidaknyamanan pada kehamilan dan mempersiapkan kondisi fisik saat persalinan.(Wirdayanti, 2019)

Terapi komplementer yang ada menjadi salah satu pilihan pengobatan masyarakat. Di berbagai tempat pelayanan kesehatan tidak sedikit ibu hamil bertanya tentang terapi komplementer atau alternatif pada petugas kesehatan seperti dokter, bidan ataupun perawat. Meskipun pengobatan tradisional/ komplementer relatif lebih aman namun bukan berarti tidak menimbulkan risiko, untuk itu ibu hamil harus memiliki pengetahuan yang mumpuni tentang pemanfaatan terapi komplementer yang aman selama kehamilan.

Pemanfaatan terapi komplementer dalam kehamilan harus diawasi dan dipastikan aman bagi ibu dan janin serta tidak menimbulkan efek negatif dalam kehamilan. Sementara informasi tentang pemanfaatan terapi komplementer yang tepat masih jarang diterima oleh masyarakat, terutama yang bersumber dari tenaga kesehatan, termasuk pada ibu hamil di wilayah kerja Puskesmas Putri Ayu Kota Jambi

\section{TARGET DAN LUARAN}

Kehamilan merupakan proses yang alamiah dimana ibu akan mengalami berbagai perubahan pada fisiologisnya yang akan berdampak juga pada psikologisnya. Terapi komplementer dapat menjadi salah satu alternatif yang aman dalam mengatasi keluhan dan menjaga stamina ibu hamil, namun perlu pengawasan dalam pemanfaatannya agar terjamin aman untuk ibu maupun janin yang dikandungnya. Untuk itu diperlukan pendidikan kesehatan kepada ibu hamil agar dapat memilih terapi komplementer yang aman bagi kehamilannya.

Melalui pendidikan kesehatan tentang terapi komplementer dalam kehamilan diharapkan terjadi peningkatan pengetahuan dan sikap ibu hamil dalam memanfaatkan terapi komplementer tersebut sehingga dapat bermanfaat dan aman untuk ibu dan janin.

\section{METODE PELAKSANAAN}

Kegiatan pengabdian masyarakat ini berupa pendidikan kesehatan kepada ibu hamil tentang terapi komplementer dalam kehamilan yang dilaksanakan pada bulan Oktober tahun 2019 sampai Januari tahun 2020 di Puskesmas Putri Ayu.

Sasaran dalam kegiatan ini adalah ibu hamil di Puskesmas Putri Ayu. Adapun kontribusi sasaran dalam pengabdian masyarakat ini adalah menjadi peserta kegiatan pengabdian, mengikuti pre dan post-test dan mendapatkan informasi tentang terapi komplementer dalam kehamilan yang aman. 
Tahapan pelaksanaan kegiatan pengabdian kepada masyarakat ini adalah sebagai berikut:

1. Kegiatan awal/persiapan

a. Mengkaji dan menganalisis data

b. Mengidentifikasi masalah

c. Menyusun proposal kegiatan pengabdian kepada masyarakat

d. Menyusun SAP dan materi serta mendasain leaflet terapi komplementer untuk disampaikan kepada sasaran

e. Menyiapkan lembar pre-test dan post-test tentang terapi komplementer dalam kehamilan

f. Mengurus izin lokasi pengabdian kepada masyarakat

2. Pelaksanaan kegiatan

a. Perkenalan antara tim pengabdian kepada masyarakat dengan sasaran

b. Penjelasan kegiatan yang akan dilakukan dalam melibatkan sasaran

c. Memberikan lembar pre-test

d. Melaksanakan peer education meliputi memberikan materi tentang terapi komplementer dalam kehamilan menggunakan leaflet.

e. Memberikan lembar post-test

f. Penutupan

3. Penyusunan laporan dan publish jurnal pengabmas

a. Merumuskan hasil pengabdian kepada masyarakat

b. Mengumpulkan dokumentasi dan lampiran yang mendukung (daftar hadir, foto-foto, dan surat-surat)

c. Membuat jurnal pengabmas dan melakukan publish jurnal

d. Menyerahkan laporan kepada tim PPPM

\section{HASIL DAN PEMBAHASAN}

Kegiatan pengabdian kepada masyarakat ini dilaksanakan bersamaan dengan kegiatan Praktik Klinik Kebidanan Komprehensif mahasiswa D III Kebidanan Stikes Baiturrahim. Dalam kegiatan ini dilakukan pemberian pendidikan kesehatan berkaitan dengan ketidaknyamanan yang umumnya dirasakan oleh ibu hamil dan cara mengatasi ketidaknyamanan dengan terapi komplementer serta diskusi tentang terapi komplementer yang dilarang untuk ibu hamil.

Setelah dilakukan pendidikan kesehatan, dilakukan diskusi tentang terapi komplementer yang boleh dan tidak boleh dilakukan pada ibu hamil. Diharapkan ibu hamil dapat mengatasi ketidaknyamanan yang dirasakan dengan terapi yang aman, sehingga ibu hamil selalu sehat dan pertumbuhan janin intrauterin tidak terganggu.

Pengabdian kepada masyarakat ini melibatkan 1 orang mahasiswa yang pada saat bersamaan juga sedang melaksanakan Praktik Klinik Komprehensif di poli KIA Puskesmas Putri Ayu.

Setelah dilakukan pendidikan kesehatan tentang terapi komplementer pada ibu hamil, dilakukan evaluasi secara lisan, didapatkan hasil :

a) Ibu mengerti perubahan fisiologis dan psikologis pada kehamilan

b) Ibu memahami bahwa terapi komplementer dapat dimanfaatkan dalam mengatasi ketidaknyamanan selama kehamilan

c) Ibu mengetahui terapi komplementer yang aman dan yang tidak aman untuk kehamilan

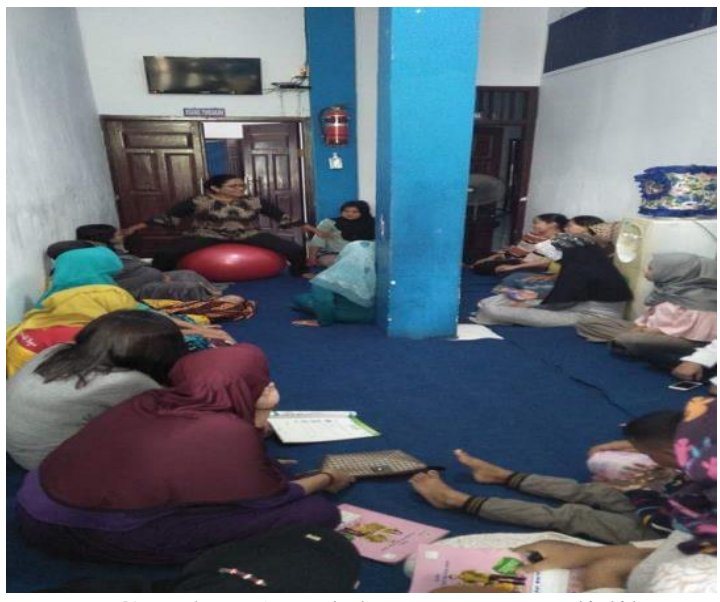

Gambar 1.Pelaksanaan Pendidikan

Kesehatan tentang Terapi Komplementer pada Kehamilan 
Terapi komplementer merupakan pengobatan tradisional yang sudah diakui dan dapat dipakai sebagai pendamping terapi konvensional medis. Pelaksanaannya dapat dilakukan bersamaan dengan terapi medis. Ibu hamil merupakan kelompok yang dianjurkan memanfaatkan terapi atau pengobatan komplementer dalam mengatasi keluhan yang dirasakan, karena dengan terapi komplementer dapat menghindari efek samping pengobatan konvesional dan memiliki kontrol yang besar terhadap kesehatan sendiri.(Wirdayanti, 2019)

Pengetahuan tentang terapi komplementer dipengaruhi oleh berbagai sumber informasi, diantaranya media massa, informasi dari sebuah produk, rekomendasi keluarga dan teman, sifat alami manusia yang ingin selalu mencoba hal-hal baru serta kemudahan akses pada terapi komplementer.(Onyapat, 2011)

Pemanfaatan terapi komplementer pada ibu hamil sangat dipengaruhi oleh pengalaman. Pengalaman merupakan sumber pengetahuan atau pengalaman merupakan suatau cara memperoleh kebenaran pengetahuan.(Notoadmodjo, 2012)

Luasnya akses informasi tentang terapi komplementer pada kehamilan sangat mempengaruhi isu yang beredar di masyarakat dan pemanfaatannya oleh ibu hamil. Keterbatasan praktik terapi komplementer dapat menurunkan minat ibu hamil untuk memanfaatkan terapi tersebut. Sebagai contoh pada pemanfaatan pijat ibu hamil, sebagian ibu merasa khawatir dengan efek samping pijat terhadap pertumbuhan janinnya. Hal ini didukung dengan penelitian Haswani (2016) mengenai pijat refleksi secara kualitatif, didapatkan hasil bahwa pijat refleksi saat ini telah diterima sebagai salah satu cara untuk menjaga kesehatan dimana masih adanya keterbatasan batasan pada praktik pengobatan ini, seperti masih ada klinik pijat refleksi yang melakukan prosedur tindakan dengan tidak benar atau tenaga ahli yang kurang profesional sehingga menyebabkan efek samping yang memperparah kondisi kesehatan pasien. Untuk itu ibu hamil perlu diarahkan dalam memilih terapis yang kompeten dan tersertifikasi.

\section{KESIMPULAN DAN SARAN}

\section{Kesimpulan}

Setelah diberikan pendidikan kesehatan tentang terapi komplementer dalam kehamilan didapatkan peningkatan pengetahuan ibu hamil tentang terapi komplementer dalam mengatasi ketidaknyamanan sehingga diharapkan ibu hamil dapat menjalani kehamilan dengan sehat, aman dan nyaman serta melahirkan bayi yang sehat baik fisik maupun mental.

\section{Saran}

Ibu hamil umumnya akan mengalami perubahan dan ketidaknyamanan fisiologis maupun psikologis, sehingga mendorong ibu untuk mengatasinya dengan berbagai cara baik medis maupun non medis, termasuk terapi komplementer. Untuk itu perlu edukasi yang komprehensif dari petugas kesehatan agar ibu hamil dapat memilih terapi komplementer yang tepat dan aman untuk kehamilannya. Tenaga kesehatan hendaknya memasukkan informasi tentang terapi komplementer dalam asuhan rutin dalam kehamilan.

\section{UCAPAN TERIMAKASIH}

Tim pengabdian kepada masyarakat mengucapkan terimakasih yang sebesarbesarnya kepada Stikes Baiturrahm Jambi atas dana dan fasilitas serta surat izin dalam melakukan pengabdian kepada masyarakat ini dan juga kepada Kepala Puskesmas Putri Ayu beserta jajarannya yang telah memberikan izin tempat melakukan pengabdian masyarakat ini sehingga kegiatan ini berjalan dengan lancer. Demikian juga ucapan terima kasih kepada ibu hamil peserta pengabdian kepada 
masyarakat yang telah bersedia mengikuti rangkaian kegiatan ini.

\section{DAFTAR PUSTAKA}

Moyad M dan Hawks JH. 2009. Complementary and Alternative Therapies, dalam Black JM dan Hawks JH. Medical-Surgical Nursing: Clinical Management for Positive Outcomes (8th Edition). Sl: Elsevier Saunders

Widaryanti, Rahayu. 2019. Terapi Komplementer Pelayanan Kebidanan Berdasarkan Bukti Scientific dan Empiris. Yogyakarta:Deepublish

Barnes et al. 2008. Complementary and Alternative Medicine Use Among
Adults and Children: United States. Journal of National Center for Health Statistics. USA

Onyiapat et al. 2011. Complementary and Alternative Medicine Use Among Adults in Enugu, Nigeria. Journal of Nursing: Department of Nurisng Sciences College of Medicine University of Nigeria

Notoatmodjo, Soekidjo. 2012. Promosi Kesehatan Dan Ilmu Perilaku. Jakarta: PT. Rineka Cipta

Haswani, Nurul et al. 2016. Perspectives on Reflexology: A Qualitative Approach. Journal of Traditional and Complementary Medicine 